\title{
New developments in science studies: the ethnographic challenge
}

\author{
K.D. Knorr-Cetina
}

Abstract. The aim of this paper is to bring together and review the results of a series of studies which, for the first time in the sociology of science, have chosen to study scientists at work through close, unmediated, ethnographic observation. The results of these studies vary with the theoretical outlook of their authors and the field of science investigated. I shall focus on what I consider to be their overlapping conceptions and concerns: first, the constructivist interpretation of scientific activities; second, the notion that the logic of research is indexical and opportunistic; third, the challenge of the concept of scientific communities and of quasi-economic models of science; and fourth, the rejection of the social-cognitive distinction and of the distinctions customarily drawn between the social and the natural sciences.

Résumé. Le but de cette étude est de réconcilier et de revoir les résultats d'une série d'études qui, pour la première fois dans la sociologie des sciences, ont choisi d'étudier des hommes de science au travail par le biais d'une observation ethnographique serrée et sans intermédiares. Les résultats de ces études varient d'après la vision théorique de leur auteur ainsi que le champ scientifique particulièrement examiné. Je me concentrerai sur leurs conceptions et leurs préoccupations qui se recoupent: tout d'abord l'interprétation constructiviste des activités scientifiques; ensuite, la notion que la logique de la recherche peut être répertoriée et relève de l'opportunisme; puis, le défi du concept des communautés scientifiques et des modèles quasi-économiques de la science; et enfin, le rejet de la distinction socio-cognitive et des distinctions habituellement établies entre les sciences sociales et les sciences naturelles.

Konstanzer Online-Publikations-System (KOPS)

URN: http://nbn-resolving.de/urn:nbn:de:bsz:352-opus-80467

URL: http://kops.ub.uni-konstanz.de/volltexte/2009/8046/ 


\section{Introduction}

The ethnography of scientific work is one of the most recent and promising developments in social studies of science. We know from other areas of inquiry that the ethnographic method is a uniquely valuable tool in the naturalistic study of social life, for ethnography attempts to render the phenomenon cogently in a manner that maintains its integrity and its nature (Matza, 1969: 5). Hence, if we wish to learn more about the process of scientific research, which, as Whitley (1972) and others have charged, has remained a "black box" to social studies of science, there can be no better choice than to embark on the direct ethnographic observation of scientists at work. In fact, it is surprising that with all the practical and theoretical interest in science, sociologists of science should not have decided much earlier to study science through close and unmediated observation.

Ethnographic studies of scientific work sprang up in the late 1970s in California, with three monographs (Latour and Woolgar, 1979; Knorr-Cetina, 1981a; Lynch, 1982) and a series of papers currently available (Latour and Fabbri, 1977; Latour, 1979; 1980a; 1980b; 1981; Lynch, 1976; 1982; Lynch, Garfinkel, and Livingston, 1983; Knorr-Cetina, 1977; 1979; 1980; 1981b; 1982; Knorr and Knorr, 1983a; 1983b; Williams and Law, 1980; Law and Williams, 1981; 1982; McKegney, 1979; 1980; Zenzen and Restivo, 1979; 1982). Other studies of this kind are in progress (e.g., Apostel et al., 1979; Jurdant, 1979) or in the process of publication (Traweek, 1982). I shall review six major studies currently available and refer to them in accordance with their geographical origin as the LaJolla (LA) study for the work of Latour et al., the Berkeley (BE) study for the work of Knorr-Cetina et al., the Irvine (IR) study for the work of Lynch,' the Keele (KE) study for the work of Law and Williams, ${ }^{2}$ the Troy (TR) study for the work of Zenzen and Restivo, and the Burnaby (BU) study for the work of McKegney.

These studies differ markedly in regard to theoretical outlook ${ }^{3}$ and scien-

1. The page quotes for Lynch's monograph are taken from his Ph.D. dissertation which constitutes the monograph (1979). Page quotes refer to manuscripts in cases in which the work is forthcoming. A dissertation by McKegney is expected to become available by the end of 1981 and is included in the references (BU 3).

2. Law and Williams locate the university department in Britain in which their study was done and the German laboratory involved in "Chinatown" and "Stiftung" respectively. I have named the study after the place where John Law and Rob Williams work, which is Keele University.

3. The Irvine study considers itself deeply indebted to the work of Harold Garfinkel. It appears to be mainly interested in the organizational properties of artifact accounts and the reaching of agreement in shop talk. The La Jolla study develops the notion of literary inscription to 
tific fields investigated. ${ }^{4}$ Yet in the scientific laboratory, ethnographers are confronted with a host of related problems and concerns. Despite their differences, ethnographic studies of scientific work raise a series of similar theoretical issues which challenge received conceptions of scientific investigation. ${ }^{5}$ The first of these issues maintains that scientific inquiry may be better understood as a process in which the world is constructed rather than depicted. The second refers to the indexical and contextually contingent properties of this process of production. A third point challenges the notion of scientific communities from a radically participant centred perspective which some laboratory studies adopt toward the networks of agents within which scientific research is embedded. Finally, ethnographies of scientific work challenge the traditional distinction between a social and a cognitive (technical) side of science, as well as the related distinction between the natural and the social sciences.

In the following, I shall present and discuss these challenges without making an attempt to remain faithful to the studies from which they originate, or to the intentions and theories of their authors. My aims are constructive, and to some degree critical. To assess the full scope of the works I have cited, the reader is encouraged to turn to the original writings.

characterize scientific work as mainly concerned with the creation and transformation of written "traces," such as measurement data and scientific reports. The Berkeley study explores the constructive (in contrast to descriptive) and socially situated nature of scientific work and the scientist as a practical reasoner. The Keele study has described scientific work in terms of the credibility model advanced in the La Jolla study and proposed several generalizations of this model. The Troy study has so far focused on the social contingencies of research also documented in other studies, and set out to develop a hierarchical complex model of scientific communication. The Burnaby study promises interesting insights in the way in which cultural universals and local peculiarities are connected in science.

4. The Burnaby study focuses on mammalian reproductive ecologists, the Troy study is done on a group working on the colloid chemistry of immiscible liquids, the Keele study involves two cell biology laboratories in Britain and Germany, the Berkeley study is based upon observations of plant protein research, and the Irvine and La Jolla study both concern fields in brain science. While the studies done in Keele, Burnaby, Troy and Irvine, refer to university research, the Berkeley and La Jolla studies do not.

5. In challenging the customary view of science, laboratory ethnographies join force with a number of recent approaches to social studies of science. I have in mind the work of Harry Collins (e.g., 1975) David Edge and Michael Mulkay (1976), David Bloor (1976), Barry Barnes (1977), or Michael Mulkay and Nigel Gilbert (1980). Also relevant here is the "cognitive" sociology of science (see footnote 6). For an overview of recent developments in social studies of science see Krohn (1980) and Knorr-Cetina and Mulkay (1983). 


\section{The constructivist interpretation}

Several laboratory studies refer to or demonstrate the constructive nature of scientific inquiry (BE 1: 670; BE 4: ch. 1; LA 2: 236 ff.; IR 2: ch. 8; KE 2: 6). In the same sense introduced by the Berkeley study (BE 1), the constructivist interpretation is held against conceptions of scientific investigation as either descriptive or as subjective, notions which locate the problem of scientific objects either in their external relations to nature or in their internal relation to human thought. In contrast, the constructivist interpretation considers the objects of science as first and foremost the result of a process of reflexive fabrication. Accordingly, the study of scientific knowledge is primarily seen to involve an investigation of how scientific objects are produced and reproduced at the site of scientific action, rather than of how natural objects are preserved in scientific statements about nature, or of how they are generated in the realm of ideas and beliefs. To give more precise meaning to the way in which scientific inquiry appears to be constructive, I will take up in turn four aspects of scientific work to which laboratory studies have given particular attention.

The first and simplest of these aspects need only be mentioned in brief. It refers to the arti-factual character of the reality within which and upon which scientists operate. It is clear that measurement instruments and other utensils of the laboratory are the product of human effort, as are the books, articles, graphs, and printouts which are used. But equally preconstructed are the source materials which scientists manipulate. Plants and test animals have been specially grown and bred, substances are multiply purified and have been bought from a specialized industry or from other labs. "Raw" materials which enter the lab ate carefully selected and "prepared" before they are used in experiments. To the observer from the outside world, the laboratory displays itself as a site of action from which "nature" is as much as possible excluded rather than included.

It will also be clear that instrumentally accomplished "observations" of masses and velocities, of $\mathrm{pH}$ values or chemical reactions differ from our ordinary everyday observations in that they intercept the course of events. We find a mundane reflection of this instrumental interception and of the arti-factual nature of the objects which result from this effort in the scientists' vernacular of skilled production, in particular in their preoccupation with "making things work" (IR 2: 161; BE 4: 7ff.). In the scientist's practical reasoning, inquiry displays itself as an activity to produce certain technical effects and not as an attempt to describe nature. As the La Jolla study emphasizes, this instrumental manufacture of knowledge in the workshop called a lab includes a concern with writing, most visible in the "literary inscriptions" represented by notes and protocols, measurement data, and research reports (LA 2: $45 \mathrm{ff}$.).

The second aspect of the constructivist interpretation specifies some of 
the properties of this process of arti-factual production. To consider a scientific object as first and foremost the result of a process of production is to imply that what happens in the process of production is not irrelevant to the products obtained. As the Berkeley study argues, this means that the products of science have to be seen as highly internally structured, independent of their external structuring through some match or mismatch with "nature" (BE 4: 9ff.). Laboratory work not only involves highly preconstructed tools and materials, it also involves decisions and interpretations, or, more precisely, it requires selections to be made. Constructive operations are decision-impregnated operations in the sense that any definition of what is or is not the case, any specification of a course of action, of a measurement device or a chemical composition is in principle a choice among alternative means and courses of action. These selections, in turn, can only be made with respect to other selections - they are based on translations into further choices, invoked as decision criteria. The choice between a filter and a centrifuge can become a question of the speed of the process or of energy savings, of access to the instrument or of effect on the outcome - all second-order selections into which first-order selections are translated.

Translations into second-order selections are an inherent feature of decision making in general, although not necessarily an obvious feature, unless decisions become thematized. Many laboratory "decisions" appear to emerge rather than to be "taken." To refer to the decision-impregnated character of constructive operations is not to embrace individual voluntarism, but rather to refer to selections which can be presented, justified, and challenged as decisions.

Scientific products can now be seen as internally constructed in terms of several orders or levels of selectivity - with respect to composing laboratory selections as well as with respect to the translations incorporated in these selections. This complexity of scientific constructions is interesting in its own right, since it seems to suggest that scientific objects are unlikely to be reproduced in the same way under different circumstances - unless of course, selections and translations are either fixed or made in a similar fashion. Recent research on multiple discoveries indicates that many allegedly independent, simultaneous discoveries are "not as equivalent, as innocent, or as simultaneous as the records of multiple discoveries would lead us to believe" (Brannigan, 1979: 450).

Selections can be called into question precisely because they are selections, that is, precisely because they involve the possibility of alternative selections. If scientific objects are selectively carved out from reality, they can be deconstructed by challenging the selections they incorporate. In scientific inquiry, the selectivity of selections incorporated into previous scientific work is itself a topic for further scientific investigation. At the same time, the selections of previous work reappear in the laboratory as tools, methods, and 
interpretations. "The mass spectrometer is the reified part of a whole field of physics; it is an actual piece of furniture which incorporates the majority of an earlier body of scientific activity" (LA 2: $242 \mathrm{ff}$.). It is clear that previous scientific selections thus change the conditions of further selections. In this sense some scientific objects are not only decision-impregnated, they are also decision-impregnating.

The third observation about scientific work relevant to an understanding of the constructivist interpretation is its transformational aspect. In the laboratory, scientific objects are not only produced, they are transformed. They may start off as a smell of some chemical reaction or as a joke somebody makes, and turn into an "idea" and subsequently into measurement data, a "scientific paper" and a "proven fact" - or the other way round. Accordingly, some laboratory studies address this transformational aspect, for example by pursuing the difference between laboratory reasoning and the reasoning presented in the scientific paper (BE4: ch. 5; BE 7; BE 8; LA 2). This transformational aspect is perhaps the main focus of the La Jolla study, according to which "facts are constructed through operations designed to effect the dropping of modalities which qualify a given (scientific) statement" (LA 2: 237). The La Jolla study lists five types of statements which range from conjectures or speculations (type 1) to unqualified, taken-for-granted statements of fact (type 5). Laboratory activity is portrayed as a constant struggle for the generation and acceptance of statements of type 4, that is, acknowledged "facts" associated with the name of an author (LA 2: $75 \mathrm{ff}$.):

The problem for participants was to persuade readers of papers ... that this statement should be accepted as fact. To this end rats has been bled and beheaded, frogs had been flayed, chemicals consumed, time spent, careers had been made or broken, and inscription devices had been manufactured and accumulated within the laboratory. This, indeed, was the very raison d'être of the laboratory. (emphasis added).

Thus, constructive operations can be characterized as selections designed to transform the subjective into the objective, the unbelievable into the believed, the fabricated into that which has been "found" and the painstakingly constructed into the objective scientific fact. The transformational aspect of constructive operations refers not only to the phenomenon that things are molded and shaped in the hands of scientific craftsmanship. As defined above, this transformational aspect corresponds to a symmetry break in the sense that the natural becomes dissociated from the social once other selections have been ruled out, and once scientists have been persuaded to substitute for a scientist's statement an object that is "real."

If we push the argument a step further, we see that there is no need to limit the notion of transformation to the achievement of facticity. In many areas, facticity is not at stake, and even if it is scientists will often neither 
hope nor attempt to arrive at statements of type 4 . Their concern with "making one's mark" and with "distinguishing" oneself points toward the differentiation of one scientist from another. The symmetry break which dissociates the natural from the social more widely dissociates scientists from each other.

Finally, we should note that it is perhaps not so much the symmetry break in itself but its consequences which are of interest here. An assertion which transforms into a "fact" aligns other statements behind it, and appears to be used to reorganize scientific arguments. Scientists will draw upon it as a starting point for further research, or employ it as an unquestioned resource in ongoing investigations. The symmetry break through which certain selections achieve a privileged status is significant precisely because it transforms these selections into presuppositions which are taken for granted or invoked as organizing factors in future selections. I take this to be the sense in which "natural laws," or successful technical inventions are similar to rules, and in which they can be seen to be associated with power. Transformations which result from constructive operations do not just reflect shifts in a neutral series of development. Rather, they reset the scene of scientific (and practical) action in that they are used to redefine the possible and the impossible, the salient and the resistant, the victims, survivors, and beneficiaries in the newly promoted order of things. Because of this, transformations are the locus of a struggle in which the form and direction of the change (and of history reconstructed) are themselves part of what is at stake.

The last issue to be raised here refers to the self-referential aspect of constructive operations. The issue may shed some light on the epistemological stance of the constructivist interpretations. It cannot be denied that this interpretation of scientific inquiry raises a series of epistemological questions. The constructivist interpretation has been promoted against the prevailing concept of inquiry as descriptive (BE 1: 673). At the same time, it has refused to accept the label "relativist" (LA 2: 180, 238), and rejected an "idealist ontology" (BE 2: 369). The Irvine study which I take to be engaged in displaying the constructive features of scientific work rejects the notion constructive which it identifies with a subjective position (IR 2: 392). Accusations of "radical subjectivism" have also been made by some of the reviews of the La Jolla study (Bazerman, 1980: 14; Cozzens, 1980: 19). Is the constructivist position then a form of subjectivism?

My own position in this respect (and the only one I can advocate here, since laboratory studies have not addressed their own epistemological stance in any detail) is quite specific and quickly sketched. Scientific practice, like social practice in general, is self-referential practice. It refers to its own conditions of reproduction, for example, by being concerned with distinguishing between facts and artifacts, in a manner similar to philosophy of science. However, this does not mean that scientists turn into realists or subjectivists 
at liberty. The Irvine study has suggested that the question of whether the production of knowledge is descriptive or constructive is "addressed anew on each occasion in which laboratory data is produced and reviewed" (IR 2: 415). I take this suggestion to be misleading in that scientists do not suddenly think that the world is an emanation of human thought when they confront the possibility of dealing with an artifact. Rather, they may think that the finding with which they are dealing in an emanation of human thought. Scientists account for an artifact in terms of a particular scientist's mistake, or simply by saying that "something went wrong," and remain naive realists all along. Scientists' reference to the status of what they know is not identical to the philosopher's reflection upon the status of human knowledge in realist or subjectivist terms, though both versions of self-reference may be equivalent in that they constitute meta-level operations.

The notion constructive as understood here includes this level. Briefly put, scientists not only accomplish (construe) their "findings," they also accomplish the meaning of this accomplishment. Characteristically, the meaning which interests the scientist has practical implications for the status of a result as usable, reliable, publishable. Accordingly, self-reference takes a practical form which often involves physical manipulation, as when the status of an object as art or fact is thematized through an attempt to replicate the finding. Reflexivity is embodied in constructive operations rather growing out of pure reflection, and the results are informed by the practical consequences which the possible outcomes entail.

Self-reference, then, is part of scientific practice, whether in the form of scientists' embodied reflexivity or in the form of a separately institutionalized, philosophical reflection. In other words, it is part of the accomplishment and contestation of scientific reality, and as such it is first and foremost subject to empirical investigation. This points in the same direction in which some have pointed by calling for an empirical epistemology (e.g., Fleck, 1979; Campbell, 1974; Apostel et al., 1979), a work philosophers of science like Toulmin (1972) and Feyerabend (e.g., 1975) have started by turning to the history of science. To borrow half a notion by Bloor (1976), we could name such a request for an empirical inquiry into matters of fact and truth a call for a strong epistemology. The strength of the position is that it does not leave epistemological questions to theoretical articulation, but instead turns them into objects of empirical research.

I consider the constructivist interpretation advanced here as non-subjectivist exactly in the sense that it considers the self-referential reflexivity of knowledge not in itself as a matter of detached reflection, but as a matter of "fact," that is, as a meta-philosophical problem of research. We can see this position as a straightforward consequence of the thesis that constructive operations embody reflexivity, or that self-reference is not just "about," but also part of practice. 


\section{Bringing space and time back in: the challenge of the "universal" nature of science}

If scientific objects reflexively embody several orders of selectivity then a major question is how the respective selections are accomplished in the laboratory. How do scientists rule out and bring in alternative possibilities, how do they reach and break up closure in ongoing work? If ethnographers of science had hoped to come up with a set of factors which neatly circumscribe this process, they were quickly disappointed. It is perhaps the single most consistent result of laboratory studies to demonstrate the locally situated, occasioned character of selections of which I take a certain indeterminacy of the process to be the most significant theoretical correlate.

Most often quoted as relevant to laboratory operations are the circumstances of the work. Literally speaking, circumstances are "that which stands around" (LA 2: 239), but the notion is also intended to invoke conditions of the larger environment (BE 2: $356 \mathrm{ff}$., BE 4: ch. 2; IR 2: $16 \mathrm{ff}$., 410, ch. 7; LA 3;TR 1: $19 \mathrm{ff}$;; BU 2: 19). Available facilities or an apparatus that works, chemicals and utensils which are in stock, journals and books available at the library, specially trained technicians or colleagues who possess a particular know-how, the kind of routine analyses offered by service labs, but also this year's policy of the Food and Drug Administration, the local occurrence of a drought or the existence of an energy crisis, all appear to be crucially relevant to that which happens in the laboratory. Events in the process itself are another source of occasioned selections. For example, rats which are about to be "sacrificed under nembutal anaesthesia by intracardial perfusion" tend to squirm, squeak, kick and wriggle free. Thus they tend to cause troubles which require ad hoc remedies. Apart from test animals, there are social agents and their individual peculiarities and specific involvements which account for another part of the contingencies of scientific work emphasized by the Troy study (TR 1: 11). Social agents also actively respond to circumstances of their work either in terms of obstacles and "troubles" (IR 2: 424), or in terms of capacities and "opportunities" which they hasten to exploit (BE 4: 59ff.; LA 3: $60 \mathrm{ff}$.). And they turn the issue around and play upon local limitations, as when they resort to papers and know-how not known in their immediate environment.

The above argument displays inquiry as characterized by an opportunistic logic which stresses the time-and-space-bound conditions of scientific work and the scientist's active role in reflexively organizing these conditions in terms of their potential resourcefulness. A second aspect of the contextual contingency of scientific work refers to the occasioned oscillation of rules and to the indexicality of selection criteria. In the laboratory, criteria and principles of which we tend to think in general terms such as "costs" or "feasibility" become relevant only in their indexical form. "Costs," for example, matter as the labor intensity of a process, its duration, or its energy 
consumption, even as the health hazards involved in using a certain chemical which is seen as potentially toxic. Thus, it is in the form of concrete, situationally specific translations in which general principles or criteria come to bear in inquiry. We can also say that general principles are "before" and "after" schematizations of higher order selections which scientists invoke to organize and account for the concrete translations of laboratory work.

Criteria oscillations which occur in scientific inquiry can be tied to the indexicality of selection criteria (LA 3: 61; BE 4: 75 ff.). The "rules" according to which choices are made appear to be "made up in going along," so that decision criteria may oscillate from one step to the next, and glaring inconsistencies between selections appear to occur quite frequently. For example, a whole research effort may be initiated "because of" the savings in energy costs it promises, yet in the process it turns out that the costs of the chemicals used never bothered the scientists. The logic of the inquiry also is an opportunistic logic in the sense that consistency cannot be presupposed, but at best results from efforts at consistency-making.

A third issue to be raised here is that the circumstantial, occasioned accomplishment of laboratory selections are not in principle individual achievements. Rather, they must be linked to a social unit of action, or held to be interactively accomplished in connection with some form of symbolic communication. This social accomplishment of constructive operations is important because it entails a dynamic of its own which manifests itself in the negotiated character of the outcomes of scientific action. For example, scientists negotiate what they choose to accept as negative evidence for a psychobehavioral effect in a conversation recorded in the La Jolla study (LA 2: 156); they negotiate whether what they see when they see "these little things" are actually certain kinds of cells as one scientist claims (IR 2: 322); or they negotiate with the whole scientific field whether a set of points on a graph paper actually represent two straight lines or a peak in a single curve (BE 4: $259 \mathrm{ff}$.). Scientists negotiate in which journal an article is to be published, who is to be an author of the publication, and whom to include among the references cited (KE 2: $6 \mathrm{ff}$.). The scientists' laboratory constructions emerge from a form of discursive interaction directed at and sustained by the arguments of others. Local exegeses of the scriptures (the authoritative writings of science) are part of this discursive interaction. Note that ethnographic studies of scientific work tend to assimilate interaction and communication, whether they focus on the "literary" activities of science (LA 2), on the scientists' "practical reasoning" (IR 2; BE 4) or on scientific "persuasion" (KE 2), or whether they address scientific work directly in terms of "communication" (TR 1).

The thesis of the contextually contingent, indexical, and interactively accomplished character of laboratory constructions challenges many received ideas about science. For example, it is directly opposed to the notion that sci- 
ence operates according to universal standards and criteria, and it defies any notion of a rationality specific to scientific inquiry. But the consequence which is perhaps most interesting here is that of the indeterminacy of scientific action. If the conditions at the research site and the circumstances of the work constitute variable occasions out of which scientific selections arise, then we cannot predict the outcome of these occasions from knowledge of single components of these circumstances. If the respective occasions are marked by a social (interactively accomplished) dynamic of its own, then we cannot predict the outcome of the situation from knowing the actors who engage in the negotiation. The indexicality and idiosyncracies of scientific work jeopardize the hope of the philosopher of science to come up with a small set of criteria which rule scientific selections. The situational contingencies and social dynamics of scientific action resist the attempt of the sociologist to specify once and for all the social and cognitive, internal and external factors which "determine" scientific construction.

Perhaps surprisingly, observers of scientific work have tended to see situational contingency in a positive light. The Troy study calls them "constitutive" to research (TR 1:24), the Berkeley study considers contextual contingency as the very principle of scientific change (BE 4:18 ff.), and the La Jolla study associates writing with the creation of order out of the noise produced in scientific work (LA 2: 245). Laboratory studies seem to derive a sense of the constitutive role of indeterminacy out of the direct observation of scientific action. However, they can also point out recent developments in thermodynamics (Prigogine) and systems theory (von Foerster) to render these observations plausible. These developments argue that information emerges out of noise, and organization out of chance events (Atlan, 1979: 47). In a communicative link between two subsystems $A$ and $B$, total dependency between the two (determinacy) implies that the information obtained from $A$ plus $B$ will be identical to that of $A$, while total independence implies that the system will break down. In regard to the amount of information of the global system, the optimum is a non-zero transmission of information between $\mathrm{A}$ and $\mathrm{B}$ and a certain amount of error (indeterminacy) in the transmission. It is in this sense that indeterminacy (corresponding to partial independence) enables ("occasions") the emergence of new information in science. The indeterminacy linked to the situational contingencies and social dynamics of inquiry makes the progressive reconstruction of knowledge possible, and, in that sense, accounts for scientific change.

The idea is perhaps best familiar to us in the case of biological evolution. Put extremely, theories of evolution demonstrate the possibility to conceive of the creation and progressive development of things out of no-thing, and invoke chance as the most effective mechanism in the process. It is the thrust of the constructivist conception to conceive of scientific reality as progressively emerging out of operations which are marked by indeterminacy and 
social contingency, without assuming it to match any pre-existing order of the real (BE 1: 673; LA 2: $244 \mathrm{ff} ., 250$ ). This is not to reiterate a biological model of scientific evolution as presented by Toulmin (1972), which is contradicted by much of what we learn from studies of scientific work. It is, however, to point to indeterminacy as a conceivably "constructive" part of scientific action, and to point to the alleged success of science as conceivably founded upon mechanisms other than that of a progressive reality match.

\section{The challenge of the scientific-community model and of quasi-economic con- ceptions of science}

In the last section, we have seen how the research site emerges from studies of scientific work as a reality sui generis, which is constitutive of characteristic features of knowledge production. Yet the research site is not a naturally bounded unit within which scientific work is confined. We have said that the contingencies of research include time- and space-bound conditions of the broader environment. In addition, these situational contingencies are traversed and sustained by social relationships which constantly transcend the site of action. The scientists' constructive operations are socially accomplished not only through in situ face-to-face interactions, but also in regard to participants' involvements outside the laboratory site.

It is probably no exaggeration to say that the notion which has been most frequently associated with the social organization of science is that of the scientific community. Scientific communities are mostly circumscribed by a specialty area and seen as small social systems with inherent boundaries and internal mechanisms of integration. Since the earliest sociological conceptions of science, these mechanisms have been characterized in terms of economic analogies. Starting from an emphasis on the role of imperfect competition (Merton), we have moved to pre-capitalist models of the scientific community in which scientific achievements are exchanged for a variety of rewards (Hagstrom, 1965; Storer, 1966), and finally to a capitalist market economy of science originally proposed by Bourdieu (1975). Here, the scientific field is the locus of a competitive struggle for the monopoly of scientific credit acquired through the imposition of technical definitions and legitimate representations of scientific objects. The market model has been modified and refined by the La Jolla study, which sees scientists as seekers and investors of credibility. Credibility accrues from credible information, that is from statements of type 4 or 5 (see above). It can in turn be converted into money, positions, recognitions, etc., and through these resources into further information, in a cycle in which reproduction for the sake of reproduction is the mark of pure, scientific capitalism (LA 2: $149 \mathrm{ff} . ;$ LA 3: $41 \mathrm{ff}$.).

Studies of scientific work which have not adopted the quasi-economic model of specialty fields such as the Keele study (KE 1;2) have either not 
addressed the issue (IR 2), or taken a critical stance (BE 4: ch. 4; BE 6). The Troy study presents a "hierarchical complex model" of the scientists' involvement in different groups held together by the degree and kind of communication entertained - a model which promises to cut across specialty groups, but has not yet been fully developed (TR 1: 23). The Keele study has employed the credibility model to account for the scientists' self-interested activities observed, but has also gone beyond this model by introducing the notion of "networking" which equally awaits further elaboration. The notion refers to the tacit connections and allocations of value through which agents establish interrelationships between people, things, and facts. It promises to lead to a network model which transcends the received concept of scientific field by focusing the attention on the structuring activities of agents.

The critique of the capitalist market model of specialty fields can be quickly sketched. First, as Edge has noted (1979: 124), the correct definition of a specialty around which much work in social studies of sciences has centred at least since Kuhn is a "meaningless concept" to be replaced by a "radically participant centred" definition of relevant collectivities. In contrast to the hierarchical complex model, for example, the capitalist market model of scientific fields does not attempt such a radically participant centred definition, but continues to presuppose professional membership groups as the relevant units of social organization in science.

Second, the capitalist market mechanism points to some untenable consequences of this presupposition. The advantage of an analogy is that it brings to bear upon a little known phenomenon mechanisms derived from a better known phenomenon which in some sense can be seen as similar to the former. Yet the mechanisms transferred from one phenomenon to the next have to remain internally consistent, or else the transfer amounts to not much more than a substitution of terms (such as "symbolic capital" for "recognition"). In economic theory, the notion of capital is linked to the idea of an accumulation of surplus value, which in turn is inherently connected to the notions of exploitation, class structure, and alienation. To make sense of this structure in a scientific specialty, we would somehow have to distinguish scientists-capitalists from scientists-workers by defining a level of symbolic capital or credibility above which scientists count as capitalists and below which they do not. However, such a procedure would be nothing less than arbitrary. Part of the difficulty is the notion of symbolic capital itself. Such capital, particularly if understood in terms of credibility or operationalized in terms of publications and professional status, is a common though graded characteristic of everyone to whom the notion scientist commonly applies. Another and more important part of the difficulty is the restricted reference of the market model, which continues to promote an internalistic view of science.

This internalism "is no longer due to the once dominant distinction be- 
tween the social and the cognitive side of science, but to a continuing limitation of the perspective to the scientists themselves" (BE 4: 134;BE 6). Scientific communities have turned into markets, and normative and functional integration has been replaced by a competitive struggle. Scientists have become capitalists, but they are still treated as though they were isolated in a self-contained, independent system of their own. Since we cannot define class differences in this system in any justifiable way, we end up with communities of petty capitalists who sustain themselves by somehow exploiting - or not exploiting? - each other. In economic theory, the existence of such community capitalism would certainly be a curiosity, in particular because those who provide the actual resources into which symbolic capital must be converted before it can be renewed are conspicuously absent from the picture. We should also note in passing that if we reintroduce an unequivocal connection between the status of the information produced by a scientist and his or her access to position, career, research money, citations, and recognition, we are back with Davis and Moore's famous theory of social stratification according to which those who achieve best earn and warrant the better "positions" in a society. While such a system might indeed be called functional, decades of sociological research have shown that it does not exist. I should like to add that the Keele study has been aware of a similar difficulty. In their first publication, the authors write:

Calculations about credibility rarely take place uninfluenced by non-credibility issues. This is, of course, a way of saying that science is constitutively social in a manner even broader than that suggested by the credibility model. To view science as the disinterested search for credibility is, in its own way, as misleading as to view it as the disinterested search for truth. (KE 1:313).

What, then, do the scientists' external involvements as displayed in the laboratory suggest in regard to the social organization of science? The scientists' practical reasoning routinely refers not only to specialty colleagues and other scientists, but also to grant agents, administrators, industry representatives, publishers, or the management of the institute at which they work. It is clear that the agents invoked do not form a professional membership group. Moreover, scientists, even specialty colleagues, may confront each other in their everyday exchanges in "non-scientific" roles in which they administer money or dispose of careers. Similarly, a government official or sales agent may negotiate with the scientific specialist the methods to be used in a research project, or the proper interpretations of a measurement result.

In short, laboratory reasoning and the involvements in which scientists perceive themselves to be entangled refer us to symbolic relationships which are transscientific, that is, to relationships which in principle go beyond the boundaries of a scientific community, however broadly defined. These symbolic relations are not primarily determined by characteristics held in com- 
mon by its members as in the case of a logical class. The social integration which emerges from this picture is based not upon what is shared, but upon what is transmitted between agents. Accordingly, relationships between agents are often construed as "resource" relationships, in which agents are interested in what is transmitted in order to convert it into something else. For example, a result in the literature is usually not just simply taken over by another scientist, but rather it will be taken over in order to be converted into a new result of the scientist making the transfer, and it will, in the process, itself undergo transformations and reconstructions.

The crucial question is, of course, in what sense the observed transscientific connections of scientists are relevant to the process of inquiry. The answer given by the Berkeley study is that these relationships emerge as the locus in which the decision criteria corresponding to laboratory selections - not necessarily the decisions themselves - are defined and negotiated. Take the case of a grant proposal. It has long been noted that research problems may be an "external" input to science which is, for example, defined by the research priorities a funding agency determines. Yet the funding agency usually does much more than simply promoting certain goals. The proposals I looked at go through many fine grained stages of problem translation and elaboration. It is exactly through these elaborations that scientists and financing agencies negotiate what the problem is, and how it is to be translated into research selections.

Now, just as there is no reason to believe that the discourse of scientists is limited to "technical" details, there is no reason to believe that the discursive interactions between specialists and non-specialists, or between scientists and non-scientists (as defined by institutional role) are limited to money transfers or other "social" matters. We may also run the danger of considering the second kind of discourse "social," whatever its content. But be that as it may, it will be plausible that discourse which bears, in an indirect way, on laboratory work cannot be limited to specialist communities. Why then should we continue to promote an internalist conception by considering these communities as the collectivities relevant to scientific work?

Finally, let me point out that the information theory analogy which I have invoked before suggests that if the substantive matters of science were completely (i.e., substantially, not financially) independent of other fields of social discourse, the relation between science and other societal areas would long have broken down. Note that it is not enough to assume that science is dependent on problem-inputs since problems which are held to be (re)defined by scientists result in purely internal descriptions. It is only if we allow for a lack of autonomy endemic to substantial matters of science that the symptoms of interrelationships which strike us in terms like "scientization" make sense. Laboratory studies thus suggest that we have to part not only with the social-cognitive distinction which most of them reject, but also with the 
external-internal distinction.

But the above analogy is also useful to remind us that the selections of the laboratory cannot be read off from the scientists' contextual involvements. Transscientific connections of inquiry are simply marked by the same kind of situated social dynamics and corresponding indeterminacy by which laboratory work is generally characterized. While this indeterminacy may prevent us from predicting single laboratory selections from knowledge of a scientist's transscientific involvements, it does not prevent us from including these involvements in our notion of the social context in which scientific work is embedded.

\section{The challenge of the social-cognitive distinction}

Studies of scientific work are clearly indebted to a particular perspective in recent science studies which argues that the "cognitive (or technical, intellectual) components" of scientific activities need to be included in the empirical investigation of science. Yet studies of scientific work have not taken over the project of "cognitive" sociology of science to determine how social and cognitive factors interact in the production of knowledge. ${ }^{6}$ In fact, most ethnographic studies of scientific work have rejected the social-cognitive distinction altogether, and with it the controversies between those who advocate a more social or more cognitive account of scientific development (LA 2: 32; BE 4: 47 ff.; cf., TR 1: 22).

We are now in a position to expound the challenge of the social-cognitive distinction by summarizing some of the arguments from our previous discussion. In general, it appears that the more closely the "cognitive" core of scientific work has been looked at, the more thoroughly social an accomplishment it has turned out to be. The social displayed itself as internal to the cognitive and technical, and the cognitive became a function instead of a separate compartment of scientific practice. It follows that it made no sense to address this practice in terms of a theoretical distinction which is at best a transient end-product of scientific work. Laboratory studies have consequently favored concepts which cut across the social-cognitive distinction and its various correlates. What, concretely, are the arguments which account for this move?

To begin with, studies of scientific work demonstrate - sometimes in minute detail - the negotiated and accomplished character of scientific objects, as indicated before. In the laboratory, it appears not to be "nature

6. Examples of the "cognitive" orientation toward science studies can be found in Whitley (1972), Nowotny (1973), Weingart (1976), or in the papers collected in Lemaine et al. (1976) and Mendelsohn et al. (1977). 
which decides," but the natural scientist, along with technicians and laboratory assistants.. Through interpretations and the negotiation of agreement, scientific reality is selectively constructed and reconstructed. What counts as true in this process emerges from social confrontation and takes the form of selections which are temporarily stabilized as non-selections. In scientific work, scientists do not "ask questions to nature." Scientists try to make something work in terms of instruments, materials, and interpretations which result from the constructions of other scientists, and they try to make it work in discursive interaction with others within and outside the laboratory. This is the first sense in which the "cognitive" core of scientific work appears to be thoroughly social.

A second sense refers to the contextual contingencies about which we have talked at some length. To a process in which selections are occasioned by circumstances and conditions in the larger environment, which is marked by a situational logic of decision making and by indexical interpretations of rules and criteria, the notion "cognitive" cannot properly be applied. It is precisely the situational mix of instruments and people, of the "symbolic" and the "material," of abstract "ideas" and particularistic considerations, and of a logic responding to this mix in a seemingly ad hoc way which jeopardizes the distinction between the "scientific" and the "non-scientific," and prompts us to talk about "contingencies" instead. If local circumstances and conditions could be sorted into two classes of variables which would show a clearcut effect on scientific work independent of time, space, particular constellations and the dynamic of the process itself, the reference to circumstances and contextual contingencies would make no sense. It is precisely because the respective factors vary over time and space, and matter only in specific, time-and-space-bound constellations in a way which is itself dependent on ongoing thematizations of events, that we need to take recourse to notions like indexicality and indeterminacy, and that we cannot employ the social-cognitive distinction.

A third argument which challenges the social-cognitive distinction has first been brought into focus by Bourdieu (1975). It says that the "cognitive" or "technical" selections of scientists are at the same time political strategies. "Every scientific choice," says Bourdieu, "the choice of an area of research, the choice of methods, the choice of the place of publication, is . . a political investment strategy, directed, objectively at least, towards maximization of strictly scientific profit, i.e., of potential recognition by the agent's competitor-peers" (1975: 22ff.). The argument is perhaps best developed and elucidated in the La Jolla study. The scientists' activities are said to be oriented toward operations on statements which transform these statements into "facts." At the same time, these operations are moves in a "political field of contention" (the scientific field) in which the stakes are set in terms of credibility and strategic positions, in terms of access to resources, invest- 
ments, and returns. The political calculation of careers and the "cognitive" struggle toward "truth" are not separate, different things in which scientists engage, but one is done through the other, so to speak. Such a narrow one-to-one connection comes close to the notion that the better scientists are those who make a career in science, which I criticized above. Yet we need not assume such a one-to-one relationship in order to accept the thesis that "cognitive" decisions are at the same time, by intention or by consequence, social strategies, which makes our original social-cognitive distinction obsolete.

Finally, the last argument against presuming distinctively social and cognitive variables which influence scientific work is that distinctions such as between the social and the cognitive, the scientific and non-scientific, or the internal and the external are routinely employed by participants themselves. They are part of the reflexivity embodied in practical action, a point discussed in connection with the epistemological consequences of the constructivist interpretation. Demarcations between different kinds of reality are the practitioner's as well as the sociologist's resource. In particular, we have heard that the transition of a scientific result from a decision-impregnated to a decision-impregnating, taken-for-granted object may be accompanied by a category change which turns a socially produced knowledge "claim" into a purely cognitive product (such as a "scientific fact," a "technical" instrument, or a "finding" about nature). The danger is, as the La Jolla study argues, that sociologists fail to critically examine the practitioner's use of the distinction when they use the same distinction as a resource in their own work (LA 2: 23). This need not be so, but it undoubtedly is mostly the case. We may also overlook our own role in assisting practitioners with making such demarcations.

\section{The challenge of the two-sciences distinction}

The rejection of the social-cognitive distinction and in general the results of ethnographic studies of scientific work have consequences for our understanding of natural science inquiry in relation to the social sciences, an issue which I would like to take up in concluding this paper (BE 4: ch. 6). In the wake of the dispute over positivism and its call for unity of the sciences, the thesis that we really deal with two kinds of sciences has become widely accepted by philosophers and social scientists alike. Most generally speaking, the distinction between the two sciences is based upon attributing symbolic quality to social as against natural reality, and upon attributing an interpretive and dynamic quality (sometimes identified with hermeneutics) to social as against natural science inquiry. In fact, new rules of social science method have been developed and defended in a continual dispute of a standard attributed to natural science investigation, and departure from this standard 
has been the declared goal of many newly launched sociological approaches.

Perhaps unsurprisingly, the standard itself has been paid little attention in the dispute. While the "positivistic" picture of inquiry has been vigorously rejected as a model for the social sciences, it has been taken at face value in regard to the natural and technological sciences. To be sure, social studies of science have portrayed in more and more detail a social side of science, and increasingly pointed out social factors which influence technical inquiry. Yet insofar as these studies have maintained the social-cognitive distinction, they have endorsed a model of inquiry which locates the heart of the natural sciences in technical operations seen as distinct from the social sciences' "symbolic" operations.

It follows that the challenge of the social-cognitive distinction counts at the same time toward a challenge of the two-sciences distinction. If natural science reality is an upshot of a methodical practice which ethnographic studies of science depict as reflexive and constructive (decision-impregnated, transformational, artifactual), as socially occasioned, subject to an indexical logic, and embodied in discourse which includes its own referent, then a large portion of the presumed distinction between the two sciences disappears. Note that philosophy itself has paved the way for a challenge of the distinction, by arguing that observations are "theory-laden," that is, symbolically constituted. The sense-making activities observed in the lab do indeed have more to do with "understanding" as an act in which experience and theoretical presupposition are fused, than with "explanation" as the "application of theoretical propositions to facts that are established independently through systematic observation."

Yet the distinction customarily made between the two sciences not only rests on a mistaken conception of natural science method, it also rests upon the assumption that causal relations in the social and cultural sciences are "malleable in the light of the development of human knowledge." Knowledge made known to the participants of social action can change these actions, while knowledge about nature is held to be of no relevance to nature itself. Nagel has made it a point to argue that such self-fulfilling or self-negating predictions are not unique to the social sciences, since observations about a series of events in the natural sciences can also influence the course of events. This, however, is seen to be "logically different" from the social sciences, presumably because of the causal agency and conceptual mediation (conscious-

\footnotetext{
7. These quotes are taken from Habermas (1971:144) who discusses the hermeneutic character of the social sciences in contrast to a model of inquiry ascribed to the natural sciences which can serve as a paradigm for the storybook image of scientific method against which anti-positivists have argued. See also Knorr ( $1981 \mathrm{~b}$ ).
} 
ness) which we attribute to human beings. ${ }^{8}$ Since the latter is relevant only in as far as it triggers a course-of-event-changing response, the fate of what remains from the original distinction between the two sciences hinges on whether the idea of causal agency can be limited to the social world.

Realist philosophy of science itself has recently argued that the idea that the source of events in natural science is always extrinsic and that the objects of natural science are patients rather than agents "is a pure prejudice" that can be traced back to a mechanical world view long outdated in physics. "Things" must be reconceived to possess powers and liabilities, and the capacity to behave in ways they actually did not behave. And laws in the realist conception are no longer seen as statements about constant conjunctions of events, but rather about the "tendencies of things which may not be actualized, and may not be manifest to men." Anscombe (1971:21) has compared natural laws to the rules of a game, and empirical events to its actual play on a particular occasion.

If laws in the natural sciences are no longer seen as constant conjunctions of events, the thesis which holds that there are no such constant conjunctions of events in social life because of an agent-related causality different from the natural world, misses the point. If causal agency is not limited to social actors, then course-of-event changing re-actions in response to appropriate interference with these agents are not distinctive to the social world, and historicity in the sense of agency-caused changes of the course of events will have to be allowed for in "nature." If natural laws can be compared to rules, then Peter Winch's famous definition of the social sciences in terms of a distinctive rule-governed character of social life becomes obsolete. Studies of scientific work add to this a conception of "rules" as in turn emergent from and articulated in scientific practice, or as associated with the self-organizing properties of this practice. Thus they assimilate social and scientific practice in a way which sees distinctions between the two sciences at best as a pursuit and not as a presupposition of this practice.

Let me add that this view is intrinsically different from any program which persuades social scientists to engage in extrinsic causal explanations of a sort attributed to the "hard" sciences (Bloor, 1976). So far, observations of "hard" science at work have not been able to spot the kind of behavior which the "strong program" pledges us to take over from the natural sciences. The challenge of an empirical epistemology advocated here is to account for the "success" of science in terms which do not presuppose a naturalistic concep-

8. See Nagel (1961) and Giddens (1976) for a more prominent counter-argument against Nagel's position.

9. See particularly Bhaskar (1978). 
tion of scientific objects, or a positivistic conception of scientific method. The laboratory observations available suggest that we not only part with the social-cognitive distinction, but also with the two-sciences distinction.

\section{Conclusion}

I have been suggesting that recent ethnographic studies of scientific work challenge the customary view of scientific inquiry on more than one account. First they suggest that scientific inquiry may be better understood as a constructive activity to produce certain technical effects than as an attempt to depict the nature of the world. Laboratory studies display the arti-factual, decision-impregnated, transformational and reflexive character of scientific operations. Second, observers of scientists at work consistently find scientific activities to be marked by a logic of the occasion: technical operations appear to be contextually contingent, rules and decision criteria change with the situation, and troubles and opportunities arise from the local circumstances of scientific work. Third, ethnographic studies adopting a radically participant-centred perspective on scientific collectivities criticize the notion of scientific communities which dominates social studies of science, and with it the idea that science is governed by quasi-economic mechanisms of exchange. Finally, laboratory studies have rejected the distinction between social and cognitive variables on various grounds, and displayed the "cognitive" as resulting from, rather than as a separate corner of scientific pursuits. As a consequence of these results, some analysts maintain that we should return to the notion of the "unity" of scientific method, arguing that natural science practice shows symbolic properties and hermeneutic features similar to those associated with social science method and procedure.

I believe these results are promising, but they also raise questions. Take the alleged contextual contingency and indexical logic of scientific research. It suggests that the true enemy of rationalistic models of science are not social accounts of scientific practice, but rather the noise (Serres, 1980), or indeterminacy, which laboratory studies take to be constitutive of scientific work. What are we to make of this indeterminacy? Are there no systemic factors, no recurring patterns of scientific practice which ethnographers of science might encounter if they were to compare different laboratory settings? Laboratory studies have not yet worked out an alternative account of how closure is reached in scientists' practical work. A similar question arises in regard to the notion of scientific communities. It has been effectively attacked, but further work will be needed to develop an appropriate alternative conception. Finally, if ethnographers of science want to counter the charges of extreme subjectivism and relativism which have been advanced against their work, they will have to address the epistemological implications of their results. To answer these questions requires working out an empirical, con- 
structive epistemology which conceives of the order generated by science as a material process of embodiment and incorporation of objects in our language and practices. I believe that the ethnographic approach furnishes a uniquely suitable tool in the search for an answer to such questions. Needless to say, we have only just begun to employ this tool in social studies of science.

\section{References}

Anscombe, G.E

1971 Causality and Determination. Cambridge, England: Cambridge University Press.

Apostel, L., et al.

1979 "An empirical investigation of scientific observation." Communication and Cognition 12(6): 3-36.

Barnes, B.

1977 Interests and the Growth of Knowledge. London: Routledge and Kegan Paul.

Bazerman, C.

1980 "Bruno Latour's and Steve Woolgar's laboratory life." Book review. 4S Newsletter $5(2): 14-19$.

Bhaskar, R.

1978 A Realist Theory of Science. Hassocks, Sussex: Harvester Press.

Bloor, D.

1976 Knowledge and Social Imagery. London: Routledge and Kegan Paul.

Bourdieu, P.

1975 "The specificity of the scientific field and the social conditions of the progress of reason." Social Science Information 14(6): 19-47.

\section{Brannigan, A}

1979 "The reification of Mendel." Social Studies of Science 9: 423-54.

Campbell, D.

1974 "Evolutionary epistemology." In The Philosophy of Karl R. Popper, edited by P.A.

Collins, $\mathbf{H}$. Schilpp, pp. 413-463. LaSalle, Illinois: Open Court Publishers.

1975 "The seven sexes: a study in the sociology of a phenomenon or the replication of experiments in physics." Sociology 9(2): 205-224.

Cozzens, $\mathrm{S}$.

1980 "Bruno Latour's and Steve Woolgar's laboratory life." Book review. 4S Newsletter 5(2): 19-21,

Edge, D.

1979 "Quantitative measures of communication in science: a critical review." History of Science 17: 102-134.

Edge, D. and M. Mulkay

1976 Astronomy Transformed. New York: Wiley.

Feyerabend, $P$.

1975 Against Method. London: New Left Books.

Fleck, L.

1979 Genesis and Development of a Scientific Fact. Chicago: University of Chicago Press (originally published in German, 1935).

Giddens, A.

1976 New Rules of Sociological Method. London: Hutchinson. 


\section{Goffman, E.}

1972 "The neglected situation." In Language and Social Context, edited by P.P. Giglioli, pp. 61-66. Harmondsworth, Middlesex: Penguin Books.

Habermas, J.

1971 Knowledge and Human Interests. Translated by J.J. Shapiro. Boston: Beacon Press.

Hagstrom, W.O.

1965 The Scientific Community. New York: Basic Books.

Jurdant, B.

1979 "Socio-epistemologie des hautes energies. Questions de methode." Strasbourg: Groupe d'Etude et de Recherche sur la Science de l'Université Louis Pasteur (manuscript).

Knorr-Cetina, K.D.

1977 "Producing and reproducing knowledge: descriptive or constructive? Toward a model

(BE1) of research production." Social Science Information 16:669-696.

1979 "Tinkering toward success: prelude to a theory of scientific practice." Theory and

(BE2) Society 8: 347-376.

1980 "The scientist as an analogical reasoner: a critique of the metaphor theory of innova

(BE3) tion." In The Social Process of Scientific Investigation, edited by K. Knorr, R. Krohn, and R. Whitley, pp. 25-52. Dordrecht: D. Reidel.

1981 a The Manufacture of Knowledge. An Essay on the Constructivist and Contextual

(BE4) Nature of Science. Oxford: Pergamon.

$1981 \mathrm{~b}$ "Social and scientific method, or "What do we make of the distinction between the

(BE5) natural and the social sciences?'” Philosophy of the Social Sciences 11: 335-359.

1982 "Scientific communities or transepistemic models of research? A critique of

(BE6) quasi-economic models of science." Social Studies of Science 12:101-130.

Knorr-Cetina, K. and M. Mulkay, eds.

1983 Science Observed: An Analytical Methodology for Science Studies. Beverly Hills, California: Sage Publications.

Knorr, K.D. and D.W. Knorr

1983a "The scientist as a literary reasoner, or the transformation of laboratory reason." In

(BE7) Science Texts, edited by J. O'Neill.

1983b "From scenes to scripts: on the relationship between laboratory research and published

(BE8) paper in science." Forthcoming.

Krohn, R.

1980 "Toward an empirical study of scientific practice: introduction." In The Social Process of Scientific Investigation, edited by K. Knorr, R. Krohn, and R. Whitley, pp. vii-xxv. Dordrecht: D. Reidel.

Latour, B.

1979 "Le dernier des capitalistes sauvages. Interview d'un biochemiste." Paris: Conserva

(LA3) toire des Arts et Metiers (manuscript).

1980a "Is it possible to reconstruct the research process? Sociology of a brain peptide." In

(LA4) The Social Process of Scientific Investigation, edited by K. Knorr, R. Krohn, and R. Whitley, pp. 53-76. Dordrecht: D. Reidel.

$1980 \mathrm{~b}$ "The three little dinosaurs or a sociologist's nightmare." Fundamenta Scientiae

(LA5) 1:79-85.

1981 "Who is agnostic or what could it mean to study science." In Sociology of Knowledge.

(LA6) Science and Art, edited by H. Kucklick. Forthcoming.

Latour, B. and P. Fabbri

1977 "Pouvoir et devoir dans un article des sciences exactes." Actes de la Recherche en

(LA1) Science Sociales 13: 81-95.

Latour, B. and S. Woolgar

1979 Laboratory Life: The Social Construction of Scientific Facts. Beverly Hills: Sage

(LA2) Publications. 
Law, J. and R. Williams

1981 "Putting facts together: a study of scientific persuasion." Social Studies of Science

(KE2) Forthcoming.

Lemaine, G., R. McLeod, M. Mulkay, and P. Weingart, eds.

1976 Perspectives on the Emergence of Scientific Disciplines. The Hague: Mouton.

Lynch, $M$.

1976 "Art and artifact in microscopy." Irvine, California: University of California

(IR1) (manuscript).

1981a Art and Artifact in Laboratory Science: A Study of Shop Work and Shop Talk in a

(IR2) Research Laboratory. London: Routledge and Kegan Paul (forthcoming).

$198 \mathrm{lb}$ "Technical work and critical inquiry: investigations in a scientific laboratory." Social

(IR3) Studies of Science Forthcoming.

Matza, D.

1969 Becoming Deviant. Englewood Cliffs, N.J.: Prentice-Hall, Inc.

McKegney, D.

1979 "The research process in animal ecology." Paper presented at the conference "The

(BUI) Social Process of Scientific Investigation." Montreal: McGill University, October.

1980 "Inquiry into inquiry: the case of wildlife biology." Paper presented at the conference

(BU2) "Science and Technology Studies - Toronto 80." Toronto: University of Toronto, October.

1981 Inquiry into Inquiry: Local Action and Public Discourse in Wildlife Ecology. Ph.D.

(BU3) dissertation, Burnaby: Simon Fraser University (forthcoming).

Mendelsohn, E., P. Weingart, and R. Whitley, eds.

1977 The Social Production of Scientific Knowledge. Dordrecht: D. Reidel.

Mulkay, M. and N. Gilbert

1980 "Accounting for error: how scientists construct their social world when they account for correct and incorrect belief." Heslington: University of York and Guildford: University of Surrey (manuscript).

Nagel, E.

1961 The Structure of Science: Problems in the Logic of Scientific Explanation. London: Routledge and Kegan Paul.

Nowotny, $\mathrm{H}$.

1973 "On the feasibility of a cognitive approach to the study of science." Zeitschrift für Soziologie 2(3): 282-296.

Serres, M.

Storer, N.W.

Le Parasite. Paris: Grasset.

1966 The Social System of Science. New York: Holt, Rinehart and Winston.

Toulmin, S.

1972 Human Understanding. Oxford: Clarendon Press.

Traweek, S.

1982 "Uptime, downtime, spacetime, and power: an ethnography of the particle physics community in Japan and the US." Ph.D. dissertation, Santa Cruz: University of California.

Weingart, $\mathrm{P}$.

1976 Wissensproduktion und Soziale Struktur. Frankfurt: Suhrkamp.

Whitley, R.

1972 "Black boxism and the sociology of science." In The Sociology of Science, edited by P.

Halmos, pp. 61-92. Keele: University of Keele.

Williams, R. and J. Law

1980 "Beyond the bounds of credibility." Fundamenta Scientiae 1: 295-315.

(KE1) 
Zenzen, M. and S. Restivo

1979 "The mysterious morphology of immiscible liquids: the discovery and pursuit of an

(TR1) anomaly in colloid chemistry." Paper presented at the conference "The Social Process of Scientific Investigation." Montreal: McGill University, October.

1982 "The mysterious morphology of immiscible liquids: a study of scientific practice."

(TR2) Social Science Information Forthcoming.

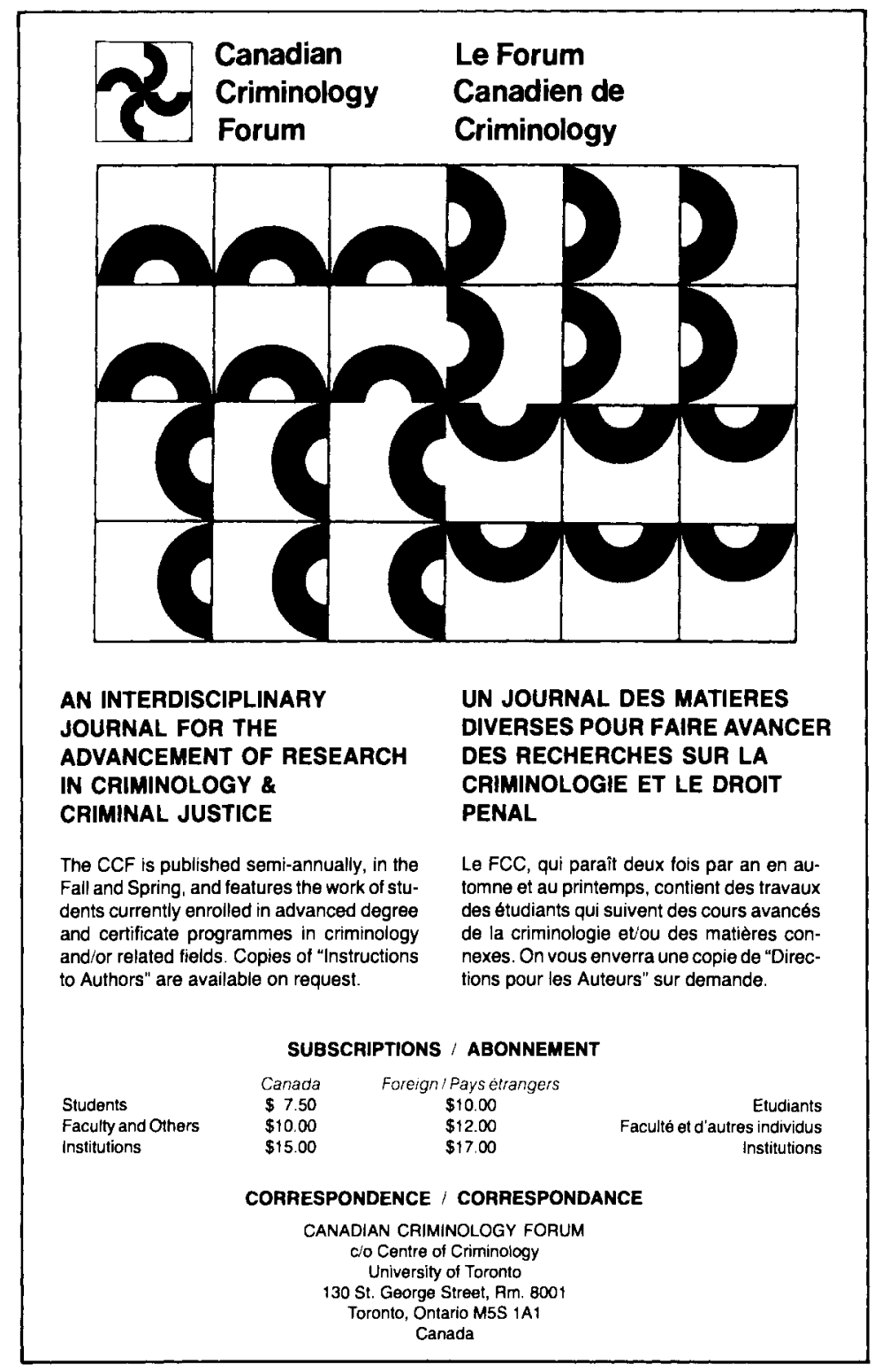

